\title{
Impfstatus hängt nur wenig von der Herkunft ab
}

den. Der Workshop fand im Rahmen eines Forschungsprojektes statt, das die „Steigerung der Impfquoten bei Kindern und Jugendlichen mit Migrationshintergrund" zum Ziel hat. Einen solchen Hintergrund haben mehr als ein Viertel der in Deutschland lebenden Kinder. In puncto Impfstatus aussagekräftig ist der Begriff nicht, wie die Daten des Kinder- und Jugendgesundheitssurveys (KiGGS) zeigen. So besitzen 59\% der Jugendlichen ohne Migrationshintergrund den vollen Impfschutz gegen Hepatitis B, aber auch 58\% der Jugendlichen mit Migrationshintergund. Jugendliche freilich, die erst nach der Geburt nach Deutschland zugewandert sind, weisen einen solchen Schutz nur zu 43\% auf. Bei der Erstimpfung gegen Masern liegen die entsprechenden Quoten bei 96\%, 95\% und 86\%.

„Insgesamt gilt für alle Impfungen, dass in Deutschland geborene Kinder und Jugendliche mit Migrationshintergrund nicht schlechter geimpft sind als solche ohne Migrationshintergrund", so das RKI. Ein wichtiger Ansatz, die Impfquoten zu steigern, bestehe darin, mehr Jugendliche zur Teilnahme an der J1-Untersuchung zu bewegen. In Deutschland Geborene nehmen sie zu 34,4\% in Anspruch, Zugewanderte nur zu 27,3\%. Dabei ist bekannt, dass etwa die Hepatitis-B-Impfquote bei Jugendlichen, die an der J1 teilgenommen haben, um 15 bis 20 Prozentpunkte höher liegt als bei solchen, die den Check ausfallen lassen - unabhängig von ihrer Herkunft.

Die Experten forderten dazu auf, besonders auf zugewanderte Kinder zu achten. Eine Möglichkeit, Impflücken zu schließen, sehen sie darin, Impfungen bei der Ankunft im Land aktiv anzubieten. Auch bei Kindern, die in den Ferien in ihre Herkunftsländer reisen, bestehe Handlungsbedarf in puncto reisespezifischer Impfungen. $\quad$ RB .

\section{Die Kultur steuert die Gefühle}

Bei Scheidungen oder familiären Krisen sind Migranten verletzbarer als Einheimische. Eine Studie ergab, dass Ehestreit und Trennung z. B. für türkische Migrantinnen die größte psychische Belastung darstellen, noch vor dem Tod eines Angehörigen oder einer schweren Krankheit.

„Diese Frauen leiden erheblich stärker als westeuropäische Frauen", so Priv.-Doz. Yesim Erim, Essen, auf dem Deutschen Kongress für Psychosomatische Medizin und Psychotherapie in Essen. Mit dem Rat, sich vom Ehemann loszusagen und ein eigenes Leben anzufangen, sei ihnen nicht geholfen: Eine solche Empfehlung verkenne, dass es für türkischstämmige Frauen keine Rollenmuster für die Gestaltung des sozialen Lebens nach einer Trennung gibt. Dies gilt mehr und mehr auch für türkische Männer. „Allein zu wohnen und allein erziehend zu sein, bereitet auch ihnen zunehmend Probleme", so Erim.
Psychotherapie in der Muttersprache Meist treffen Migranten auf deutschsprachige Psychotherapeuten. „Dies ist insofern problematisch, als viele psychische Belastungen nur vor dem Hintergrund ihres kulturellen Kontexts verstehbar sind", so Erim. Eine muttersprachliche Behandlung senke zudem die Hemmschwelle für die Inanspruchnahme.

Nach neueren Untersuchungen bestimmen kulturelle Normen und Erwartungen unseren Gefühlshaushalt viel stärker als bislang angenommen. „Dem müssen wir Rechnung tragen und die Psychotherapie interkulturell ausrichten", forderte Erim. Während z.B. eine Abtreibung in Russland nur selten ein psychisches Trauma bei den Betroffenen auslöse, gehe sie in den USA und auch in Deutschland sehr häufig mit einer schweren seelischen Krise einher. Der kulturelle Standard eines Landes entscheidet mit darüber, was einen Menschen seelisch krank mache. „N Nur wenn

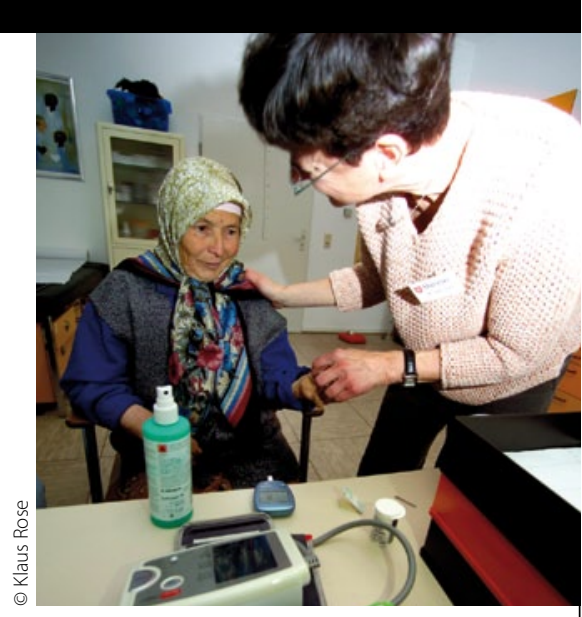

Die Kenntnis des kulturellen Hintergrunds erleichtert die Versorgung.

wir uns auf die Denkweise der Migrantinnen und Migranten einlassen, wird es uns gelingen, die Akzeptanz von Psychotherapie bei den Zugereisten zu erhöhen", so Erim. Dies sei zwingend notwendig, da Migranten häufiger an Depressionen und anderen seelischen Leiden erkrankten als Einheimische. 